\title{
ANALISIS KORELASI KEMUNCULANSPREAD F DANSINTILASI IONOSFER DI WILAYAH BARATINDONESIA MENGGUNAKAN DATAIONOSFER AGAM KOTOTABANGSUMATERA BARAT
}

\author{
Usman Malik ${ }^{1 *}$, Putri Juli Andini ${ }^{1}$, Asnawi Husin ${ }^{2}$ \\ ${ }^{1}$ Fisika, FMIPA, Universitas Riau, Jl. Prof. Dr. Muchtar Lutfhi Simpang Panam Pekanbaru, Indonesia \\ ${ }^{2}$ Lapan, Bandung, Indonesia \\ *e-mail: usman.malik@lecturer.unri.ac.id
}

\begin{abstract}
ABSTRAK
Telah dilakukan penelitian untuk mengetahui korelasi kemunculan spread F dan sintilasi ionosfer di wilayah barat Indonesia. Metode yang digunakan adalah metode interpretasi data dengan menggunakan komputasi, dimana semua data yang telah diperoleh diolah menggunakan software. Hasil dari penelitian untuk mengetahui persentase kemunculan spread $F$ dan sintilasi. Kejadian terendah spread F terjadi pada tahun 2008 sekitar 45\% dan mengalami kenaikan pada tahun 2011 sebesar 70\%. Kejadian terendah sintilasi terjadi pada tahun 2010 sekitar 13\%. Kejadian ini disebabkan oleh aktivitas matahari berada pada fese minimum. Tahun 2013 sintilasi mulai mengalami kenaikan sekitar $75 \%$ yang mana kejadian ini untuk $S_{4} \geq 0,6$. Tingkat korelasi antara spread $F$ dan sintilasi sedang, karena nilai $R$ sama dengan 0,4. Hal ini dipengaruhi oleh aktivitas matahari, apabila aktivitas matahari rendah nilai $R$ sama dengan $O$ ( tidak berkorelasi), sedangkan saat aktivitas matahari tinggi terjadi korelasi dengan nilai $R$ sama dengan 0,6 .
\end{abstract}

Kata Kunci: Ionosfer; Spread F; Sintilasi; Korelasi; Aktivitas Matahari.

\section{ABSTRACT}

[Title: Analysis of Correlation Appearance of Spread F and Ionosphere Syncilation in West Indonesia Using Agam Ionosphere Data Koto Tabang Barat Sumatera Barat] This reseach has been done to know the correlation between spread $F$ appearance and scintillation ionosphere on west region Indonesia. The method has been used is data interpretation using computational way, then all of data is processed using matlab software. The occurance of spread $F$ was minimum in 2008 with it value respectively around 45\%. In 2011 the spread $F$ was beginning to increase with it value respectively around 70\%. The occurance of ionospheric scintilation was minimum in 2010 with it value respectively around 13\%. These occurances were due to a minimum phase of solar activity. In 2013 the scintilation was beginning to increase with it value respectively around $75 \%$ in which the occurance was selected for $S_{4} \geq 0,6$. The correlation level between spread $F$ and scintilation is medium, because the value of $R$ aquals 0,4 this case is be affected by solar activity. The value of $R$ is $O$ (no correlation) at weak solar activity and 0,6 at high solar activity.

Keywords: Ionosphere; Spread F; Scintillation; Correlation; Solar Activity.

\section{PENDAHULUAN}

Bumi kita dilingkupi dengan lapisan atmosfer. Atmosfer terdiri dari bagian netral dan bagian ber-ion. Atmosfer yang banyak mengandung ion disebut ionosfer. Lapisan ionosfer berada pada ketinggian sekitar $50 \mathrm{~km}$ hingga 1000 $\mathrm{km}$ dan terdiri dari ion-ion dan elektron-elektron (Mcnamara, 1991). Gangguan kerapatan elektron di lapisan ionosfer memiiki beberapa variasi. Kerapatan elektron pada ionosfer bergantung pada waktu (siklus sunspot, harian, musiman) dan lokasi (kutub, lintang terendah). Gangguan kerapatan elektron pada lapisan ionosfer, diantaranya berupa fenomena spread F dan sintilasi.

Fenomena spread F dan fenomena sintilasi merupakan fenomena ionosfer yang terjadi di daerah ekuator yang dapat menggangu sistem komunikasi sinyal pada satelit. Informasi gangguan spread F dan gangguan sintilasi di ionosfer berguna untuk memberikan informasi gangguan cuaca antariksa bagi pengguna radio komunikasi, satelit komunikasi dan satelit navigasi, oleh karena itu untuk mengetahui seberapa besar keterkaitan 
antara fenomena spread $F$ terhadap fenomena sintilasi ionosfer maka dilakukan penelitian dengan menggunakan analisis korelasi pada kedua parameter tersebut.

Analisis korelasi dan regresi bertujuan untuk mengukur kekuatan hubungan linier antara dua variabel. Analisis regresi digunakan untuk memperoleh bentuk hubungan antara dua variabel, regresi bisa berupa regresi positif dan regresi negatif. Analisi korelasi digunakan untuk mengetahui eratnya hubugan antara dua variabel, koefisien korelasi sama dengan $\mathrm{R}$ yang mana nilai dari korelasi mempengaruhi hubungan antara dua variabel yaitu spread F dan sintilasi.

Spread F merupakan penyebaran pemantulan gelombang radio di daerah $\mathrm{F}$ akibat ketidakstabilan ionosfer di daerah ekuator (ESF, Equatorial spread F). Spread F dapat dibagi menjadi 3 bagian yaitu penyebaran pantulan dalam rentang ketinggian (range spread), dalam rentang frekuensi (frekuensi spread) dan spread F campuran (gabungan antara range spread dan frekuensi spread) (Tarigan dan Muslim, 2009).

Sintilasi ionosfer merupakan perubahan secara cepat pada fasa dan amplitudo sinyal satelit karena adanya perubahan kerapatan lapisan ionosfer. Sintilasi ionosfer ini dapat menyebabkan fading pada sinyal, cycleslip, loss of lock yaitu penerima kesulitan melakukan penguncian sinyal satelit, menurunkan sistem navigasi satelit (Asnawi, 2013). Gangguan sintilasi ionosfer dinyatakan dengan indeks sintilasi ionosfer yang saat ini sudah sering digunakan adalah indeks $\mathrm{S}_{4}$ yang mana menyatakan intensitas amplitudo sintilasi dan fasa sintilasi yang berpengaruh terhadap alat ukurnya. Sintilasi yang kuat terjadi ketika $\mathrm{S}_{4}>0,6$ dan berkaitan dengan banyaknya hamburan kuat sinyal di ionosfer.

\section{METODE PENELITIAN}

Alat dan bahan yang digunakan untuk penelitian sebagai berikut:

Tabel 1. Instrumen penelitian

\begin{tabular}{lll}
\hline No & Nama Alat & Fungsinya \\
\hline & & Mengolah dan \\
menganalisis data \\
sekunder
\end{tabular}

\begin{tabular}{lll} 
2. Data GPS sintilasi & $\begin{array}{l}\text { Sebagai sumber data } \\
\text { sekunder }\end{array}$ \\
3. Data ionosonda & $\begin{array}{l}\text { Sebagai sumber data } \\
\text { sekunder }\end{array}$ \\
& spread F & $\begin{array}{l}\text { Software yang } \\
\text { digunakan untuk } \\
\text { analisis statistik } \\
\text { sederhana dan analisis } \\
\text { korelasi. }\end{array}$ \\
\hline
\end{tabular}

Metode yang digunakan pada penelitian ini merupakan pengolahan data sekunder dengan menggunakan software matlab dan mikrosoft excel. Data sintilasi ionosfer diambil dari pengamatan ISM (Ionospheric Scintillation Monitor) Balai Pengamatan Antariksa dan Atmosfer (BPAA) Kototabang Sumatera Barat. Data Spread F diambil dari Ionosonda FMCW dari BPAA Kototabang Sumatera Barat.Analisis data dapat dilakukan setelah data diolah terlebih dahulu. Langkahlangkah dalam mengolah data yang digunakan untuk kedua fenomena tersebut, yaitu fenomena sintilasi dan spread F sebagai berikut :

1. Data yang digunakan pada tahun 2008 hingga 2013.

2. Data diolah dengan softwareMatlab dan Microsoft Excel.

3. Waktu kejadian yang ambil yaitu jam 11.00 LT hingga 23.00 LT.

4. Hitung persentase dari spread F dan sintilasi ionosfer

5. Analisis Korelasi Sintilasi dan Spread F

\section{HASIL DAN PEMBAHASAN}

Hasil penelitian fenomena spread $\mathrm{F}$ dan sintilasi ionosfer di Agam Kototabang Sumatera Barat serta perbandingan kedua fenomena tersebut 
1. Grafik persentase maksimum dan minimum spread F ionosfer

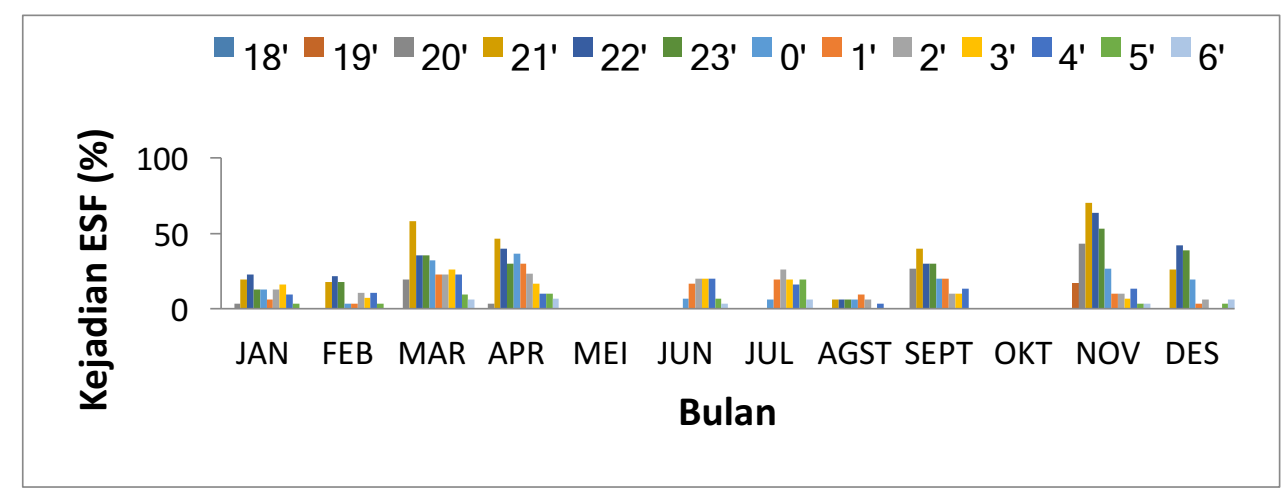

Gambar 1. Persentase maksimum kemunculan spread F tahun 2011.

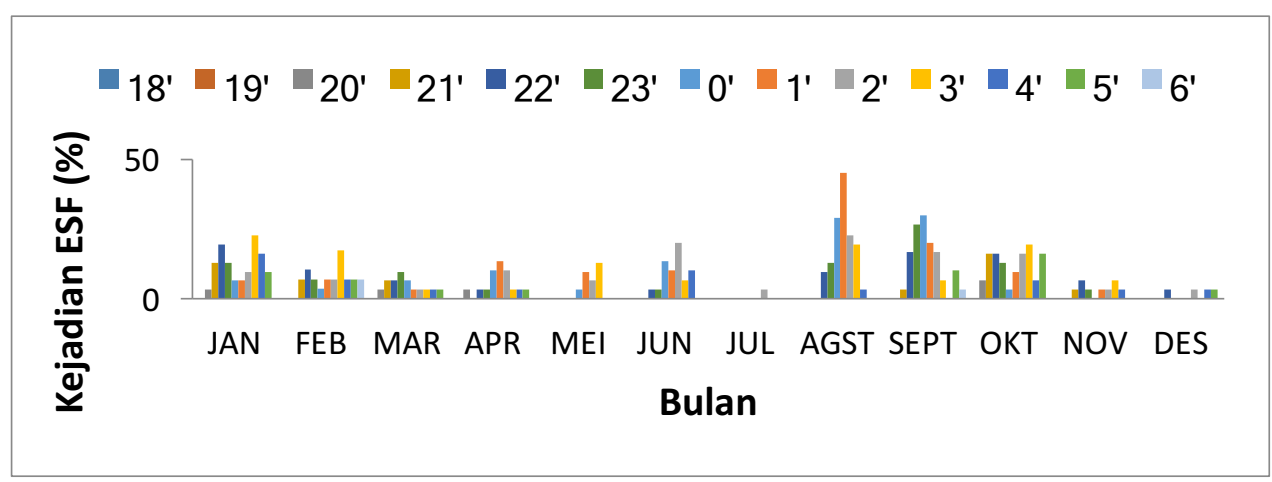

Gambar 2.Persentase minimum kemunculan spread F tahun 2008.

Persentase kemunculan spread $F$ maksimum terjadi pada tahun 2011 sekitar $70 \%$ dan persentase minimumnya terjadi pada tahun 2008 sekitar 45\%.Spread F maksimum terjadi karena adanya ketidakstabilan ionosfer di daerah ekuator yang mana pada saat itu aktivitas matahari dalam fase maksimum sehingga terjadi perubahan kerapatan eletron yang banyak, sedangkan spread F minimum aktivitas matahari dalam fase minimum dan perubahan kerapatan elektron sedikti (Tarigan dan Muslim, 2009).

2. Grafik persentase maksimum dan minimum sintilasi ionosfer

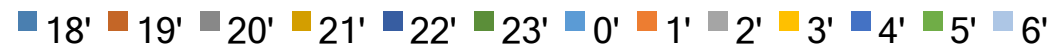

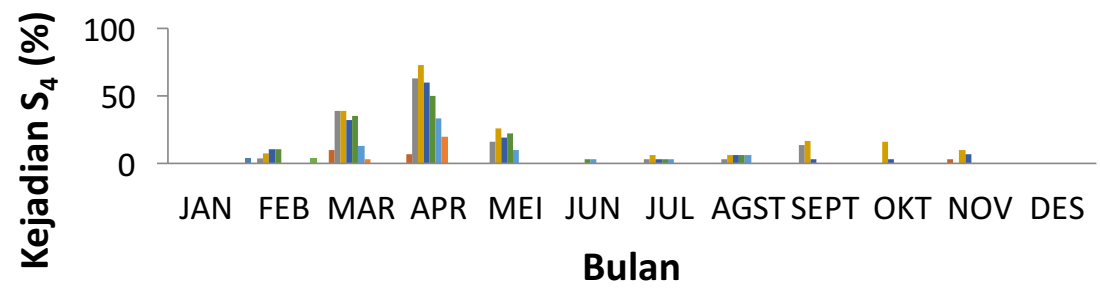

Gambar 3.Persentase maksimum kemunculan sintilasi tahun 2013. 


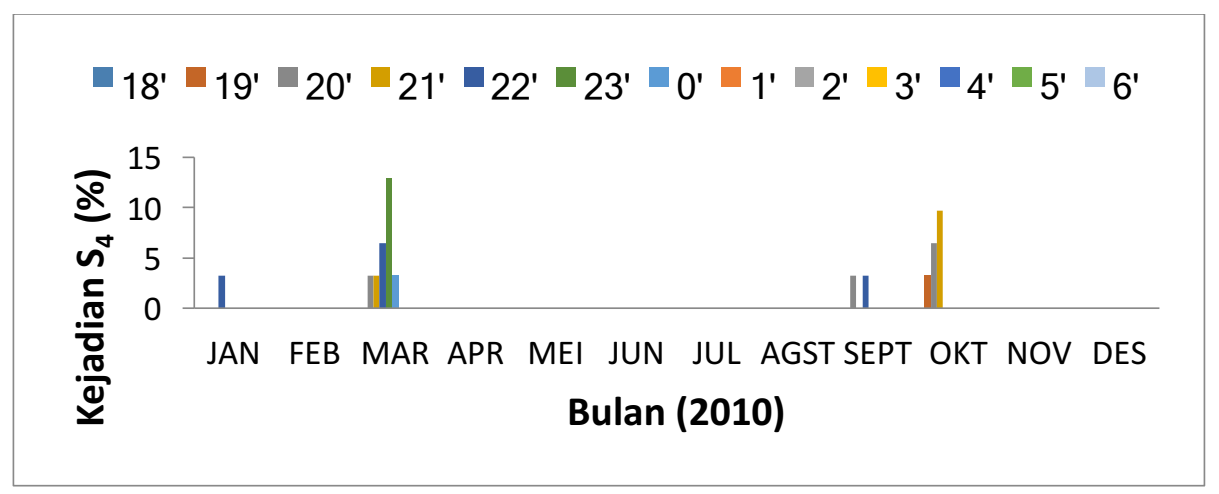

Gambar 4. Persentase minimum kemunculan sintilasi tahun 2010.

Peningkatan sintilasi dibulan ekuinok terkait dengan aktivitas mahatari yang mengakibatkan terjadinya ketidakstabilan ionosfer di lapisan F. Aktivitas matahari dibulan ekuinok disebabkan oleh gerak semu matahari. Pergerakan matahari tersebut akan menyebabkan perubahan yang besar terhadap kandungan ion dan elektron di ionosfer. Aktivitas matahari dengan

\begin{abstract}
kemunculan sintilasi ionosfer sebanding lurus, kemunculan sintilasi maksimum terjadi pada tahun 2013 sekitar 75\% disebabkan oleh aktivitas matahari pada tahun tersebut tinggi, sedangkan kemunculan sintilasi minimum terjadi pada tahun 2010 sekitar 13\% disebabkan aktivitas matahari rendah (Tsunoda, 1985).
\end{abstract}

3. Analisis Korelasi Spread F dan Sintilasi Ionosfer

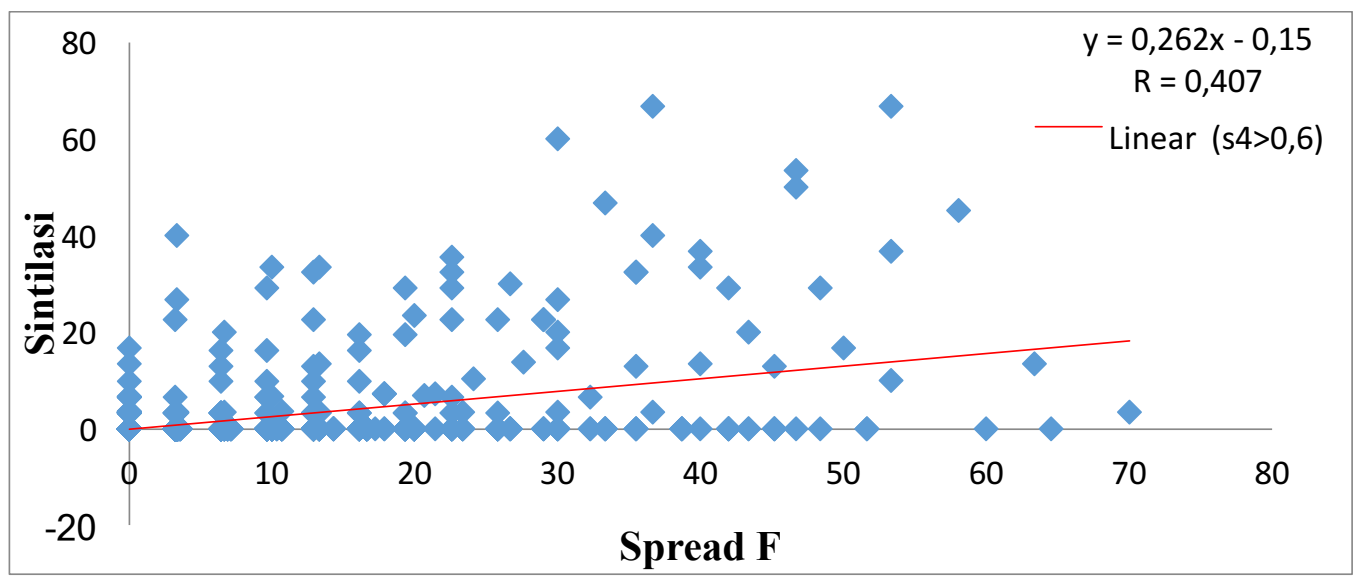

Gambar 5. Hubungan Spread F dan Sintilasi dengan niali batas $S_{4}>0,6$.

Gambar 4.5 yang telah diperoleh terlihat bahwa tingkat hubungan kedua fenomena sedang, dengan nilai koefisien korelasi $\mathrm{R}=0,4$ yang artinya sedikit kemungkinan fenomena spread F dan sintilasi ionosfer muncul bersamaan. 


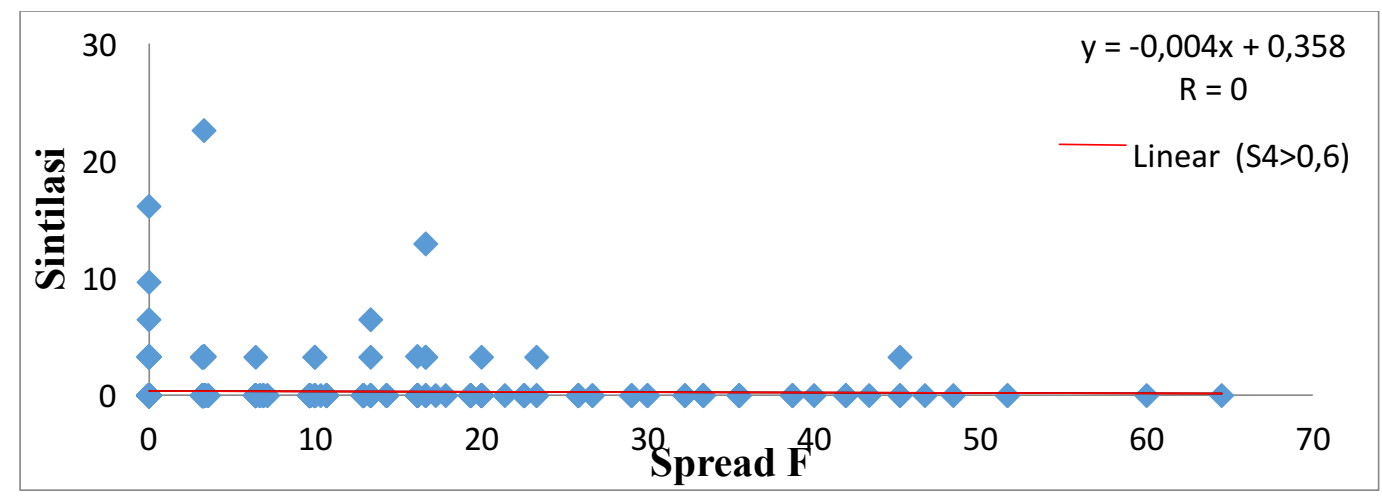

Gambar 6. Hubungan spread Fdan sintilasi dengan nilai batas $S_{4}>0,6$ pada saat aktivitas matahari rendah.

Aktivitas matahari rendah yaitu pada tahun 2008 hingga tahun 2010, dapat mempengaruhi munculnya kedua parameter. Gambar 6. Hubungan spread F dan Sintilasi dengan nilai batas $\mathrm{S}_{4}>0,6$. Nilai Korelasi koefisien $\mathrm{R}=0,063$ yang artinya kedua parameter tidak berkorelasi.

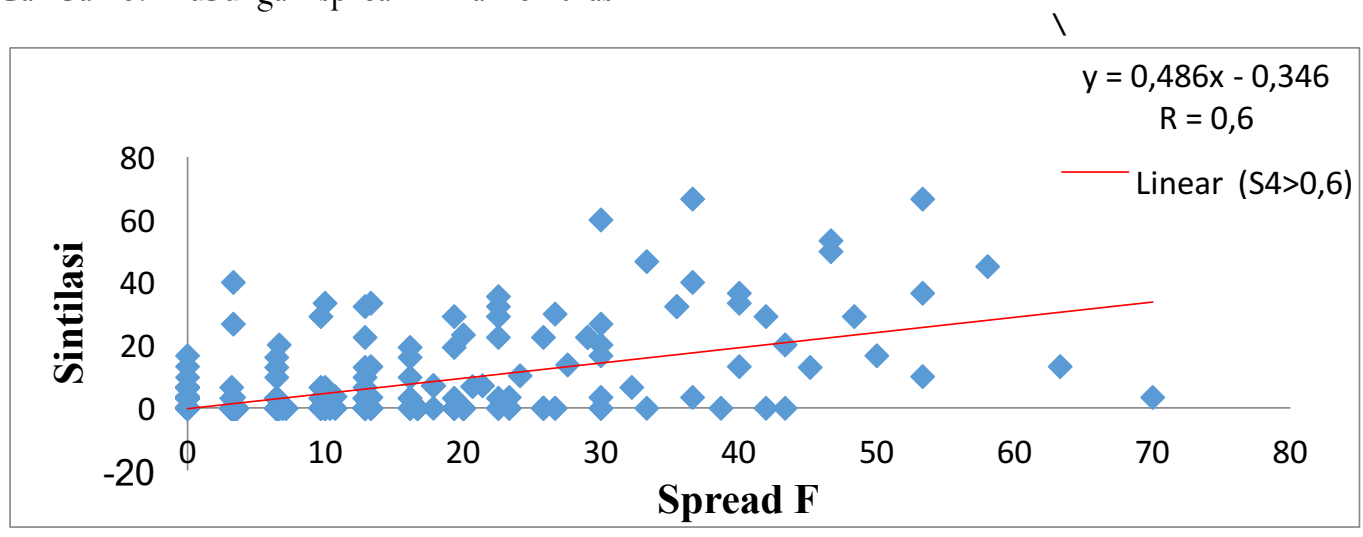

Gambar 7. Hubungan spread $F$ dan sintilasi dengan nilai batas $S_{4}>0,6$ pada saat aktivitas matahari tinggi.

Gambar 7 terlihat bahwa saat aktivitas matahari tinggi tingkat hubungan spread $F$ dan sintilasi kuat dengan nilai korelasi (R) sebesar 0,6. Aktivitas matahari dapat mempengaruhi kemunculan spread $\mathrm{F}$ dan sintilasi.

\section{KESIMPULAN}

Berdasarkan hasil penelitian dan analisa data yang telah dilakukan maka didapatkan kesimpulan sebagai berikut:

1. Hasil persentase yang telah diperoleh dapat dilihat bahwa kemunculan spread $\mathrm{F}$ maksimum terjadi pada tahun 2011 sekitar $70 \%$ dan minimum pada tahun 2008 sekitar 45\%. Hasil persentase sintilasi maksimum terjadi pada tahun
2013 sekitar 75\% dan minimum pada tahun 2010 sekitar 13\%.

2. Nilai dari koefisien korelasi spread F dan sintilasi sama dengan 0,4 yang mana tingkat hubungan dari parameter tersebut sedang. Artinya kemunculan kedua parameter tersebut bisa saja bersamaan dan tidal muncul secara bersamaan.

\section{DAFTAR PUSTAKA}

Asnawi. 2013. Analisis Statistik Kemunculan Sintilasi Ionosfer Daerah Lintang Rendah Indonesia Berdasarkan Data Pengamatan di Stasiun Kototabang. Majalah Sains dan Teknologi Dirgantara 8(2): 40-47. 
Bayong, Tjasyono. 2006. Ilmu Kebumian dan Antariksa.Bandung: PT Remaja Rosdakarya.

Hadi, Sutrisno. 2004. Statistik. Andi: Yogyakarta.

$\mathrm{J}$, Rotger. Influence of spread $\mathrm{F}$ on HF radio system. Agard Conference Proceedings on Radio System and the Ionosphere. 173: 1970.

Kondrate'ev, K Ya (ED). 1973. Radiation Characteristics of the Atmosphere and Earth's Surface. Amerind Publishing Co.Pvt.Ltd: New Delhi.

Mcnamara, LF.1991.

The IonosphereCommunications, Surveillance, and Direction Finding. Krieger Publishing Company: Florida.

Nguyen, Shin Hoa, dkk. 2006. Learning Sunspot Classification. Fundamenta Informaticae. Hal: 1-15.

Poole, Ian. 2005. Cellular Communications Explained. Elsevier: UK

Sari, Dwi Komala.2016. Analisis Morfologi Gangguan Sintilasi Ionosfer di Indonesia. Skripsi: Universitas Riau.

Soegeng, R.1994. Ionosfer. Jakarta : Andy Offset.

SWS, 2015. The Sun and Solar Activity "The Ten Centimetre Solar Radio Flux". Space Weather Service, 2015.

Tarigan, Mumen dan Buldan Muslim. 2009. Variasi Ketinggian Lapisan F Ionosfer pada saat Kejadian Spread F. Prosiding Seminar Nasional Penelitian, Pendidikan, dan Penerapan MIPA Fakultas MIPA : Universitas Negeri Yogyakarta.

Zwitter, Tomaz. 2011. Solar Flare. University of Ljubljana: Slovenia 